\title{
A produção de conhecimento em Educação Física e saúde em periódicos brasileiros
}

\section{I ${ }^{1}$ Alessandro Demel Lotti, ${ }^{2}$ Carlos Fernando Barreto de Oliveira, ${ }^{3}$ Juliana Rocha Adelino Dias, ${ }^{4}$ Eduardo Oliveira Borges, ${ }^{5}$ John Koumantareas, ${ }^{6}$ Rogério Cruz de Oliveira I}

Resumo: O objetivo do estudo foi analisar a produção de conhecimento em Educação Física e saúde em periódicos brasileiros. Para tanto, desenvolveu-se pesquisa bibliográfica na base de dados Lilacs. A coleta de dados se deu por meio do descritor "educação física and saúde" e considerou publicaçóes no período entre 1997 e 2017. A amostra consistiu em 46 artigos, os quais foram caracterizados quanto a autoria, periódico, avaliação no sistema Qualis Capes, tipo de estudo, abordagem metodológica, instrumentos de coleta de dados, amostragem metodológica, temáticas abordadas, área de diálogo e conceito de saúde. Os resultados apontaram que a produção científica tem sido demanda por pesquisadores brasileiros e com enfoque na temática da atuação profissional, majoritariamente publicados em revistas com avaliação B1 e B2. Embora a vertente teórica das Ciências Humanas seja predominante, a abordagem metodológica quantitativa ainda possui maior número de publicaçôes. Quanto ao conceito de saúde, a perspectiva ampliada esteve presente em 17 estudos, porém 26 estudos não conceituaram saúde, que consideramos um fator preocupante. Concluiu-se que a produção de conhecimento em Educação Física e saúde em periódicos brasileiros é diversa em temáticas e abordagens, entretanto, ainda carece de aprofundamento sobre o conceito de saúde.

> Palavras-chave: conhecimento; ciências sociais; periódicos.

\author{
${ }^{1}$ Universidade Federal de São \\ Paulo. Santos-SP, Brasil (alex.lotti@ \\ gmail.com). \\ ORCID: 0000-0002-4805-3633 \\ ${ }^{2}$ Universidade Federal de \\ São Paulo. Santos-SP, Brasil \\ (carlosfboliveira@gmail.com) \\ ORCID: 0000-0002-1960-3640 \\ ${ }^{3}$ Universidade Federal de São \\ Paulo. Santos-SP, Brasil (juliana. \\ dias@icloud.com). \\ ORCID: 0000-0002-0674-7813 \\ ${ }^{4}$ Universidade Federal de São \\ Paulo. Santos-SP, Brasil (borges- \\ eduardo@hotmail.com). \\ ORCID: 0000-0003-1328-7584 \\ ${ }^{5}$ Universidade Federal de São \\ Paulo. Santos-SP, Brasil (john@ \\ santos.sescsp.org.br). \\ ORCID: 0000-0002-3003-8005 \\ ${ }^{6}$ Universidade Federal de São \\ Paulo. Santos-SP, Brasil (rogerio. \\ unifesp@gmail.com). \\ ORCID: 0000-0002-8615-0397
}

Recebido em: 08/08/2019 Aprovado em: 20/09/2019 Revisado em: 23/01/2020 


\section{Introdução}

Segundo Silva (2005), é recente a história das universidades no Brasil em comparação a países da Europa e mesmo alguns países das Américas, "[...] uma vez que contamos em décadas e não em séculos a história das universidades brasileiras" (p.48). A autora afirma que esse desenvolvimento se deu como resposta do Estado aos desafios impostos pela conjuntura, principalmente no que se refere à saúde, à higiene e aos problemas agrícolas. Afirma ainda que a institucionalização de uma política brasileira de ciência e tecnologia se iniciou apenas após a década de 1950 .

A Educaçáo Física (EF) no Brasil, desde cedo, esteve penetrada e influenciada pela ciência moderna do século XIX; porém, os vínculos mais estreitos com a ciência começaram a aparecer nos anos de 1970 (SILVA, 2005). Segundo Paiva (2003), o campo da EF no Brasil foi se criando como um espaço social de disputas sobre as formas de pensá-la, o que resultou em diferentes abordagens, utilizando-se de conhecimentos advindos de diferentes campos. O problema para a autora não está no estabelecimento de relaçóes entre a $\mathrm{EF}$ e os campos médico, pedagógico ou esportivo, mas sim em sua subordinação frente a estes.

Assim, Paiva (2003) afirma ser importante pensar a EF sem abandonar seu processo de cientificização, pois considera que somente com a atividade epistemológica ela não deixará de sucumbir aos modismos do mercado. Bracht (2003) considera que estamos adentrando em um momento histórico nas sociedades ocidentais modernas, em que estaria ocorrendo um processo de desinstitucionalização ou destradicionalização das práticas sociais, levando à construção de identidades mais fluídas e em constante reelaboração. Segundo Nóbrega (2005), não é possível classificar a EF como Ciência Natural ou Humana, e uma tentativa de hegemonização não seria interessante, pois eliminaria o debate interno, limitando a produção científica a uma especialidade ou concepção teórica. Entretanto, Bracht (2003) afirma que não se pode dizer o que é certo e o que é errado em EF, nem mesmo uma verdadeira EF.

Segundo o autor, no universo simbólico construído pela EF, inicialmente o sentido de intervenção aceito e legitimado foi o pedagógico, dando caráter educativo às práticas ginásticas, esportivas e de lazer. Para Bracht (2003), a legitimação pedagógica ainda está presente no discurso que vincula as práticas corporais à saúde, considerando que este discurso tem efetividade duvidosa. Para Kunz (2007), essa mesma justificativa foi referenciada com base na simples compreensão de que a EF e as práticas corporais 
fomentassem, via de regra, a promoção da saúde, figurando como um dos principais objetivos na sua prática social, principalmente no ambiente escolar.

Quanto à produção científica, Silva (2005) considera que, após 1964, ciência e tecnologia passaram a ser vistas como instâncias estratégicas pelo governo. Assim, a EF teve que demonstrar que não apenas fazia uso dos conhecimentos científicos, mas também era capaz de produzi-los. Nesse contexto, surgiram, por exemplo, em 1978 o Colégio Brasileiro de Ciências do Esporte (CBCE). Um ano depois foram criados o Congresso Brasileiro de Ciências do Esporte (CONBRACE) e a Revista Brasileira de Ciências do Esporte (RBCE). ${ }^{1}$

Segundo Silva (2005), nos anos de 1980, houve uma tentativa de diversificar a produção científica no Brasil, principalmente no horizonte das dimensôes cultural, socioeconômica e política, haja vista que, até então, tinha o predomínio dos métodos quantitativos com temáticas biomédicas, esportes de rendimento e avaliação física. Como consequência, a autora aponta que nos anos de 1990 a EF estreitou-se com diferentes áreas das Ciências Humanas.

Sobre a dualidade entre Ciências Naturais e Humanas, Feron e Silva (2007) alertam para a inexistência de verdades absolutas, mas sim verdades que se complementam:

Esse movimento, visualizado por alguns como um momento de "crise", poderia ser encarado como um tempo de superação, de transposição do "paradigma" das ciências naturais em prol das ciências humanas [...]. Entretanto, mesmo esses novos "modos de olhar", pautados nas ciências humanas, não possibilitam de maneira alguma chegar a uma "verdade absoluta" ou mesmo a uma "verdade relativa", mas sim a muitas "verdades diferentes" e em diversos domínios distintos. E é à luz desse apontamento que acreditamos que aqueles que professam essa doutrina no campo da produção do conhecimento na educação física não percebem essa condição, qual seja, a de que o estatuto das ciências humanas, tanto quanto o das ciências naturais, opera numa mesma lógica da produção discursiva da "verdade" (aspas dos autores, p. 117).

Isso significa dizer que as Ciências Humanas não são menos científicas que as Ciências Naturais, muito menos estão em oposição. Na ótica de Santos (1993, p.9), "[...] começa a deixar de fazer sentido a distinção entre ciências naturais e ciências sociais”. Pelo contrário, se complementam, pois um mesmo ato externo de um ser humano pode corresponder a sentidos distintos, cabendo à ciência compreendê-los.

Segundo Molina Neto et al. (2006), a produção de conhecimento em EF “é um assunto inesgotável, [sic] e está circunstanciado ao tempo histórico e ao contexto da 
cultura em que se realiza" (p.161). No bojo desse debate, tem figurado uma série de subtemas, dentre os quais os que dizem respeito às práticas corporais. ${ }^{2}$ Grande parte dessa discussão gravita em torno das contribuiçóes desta à promoção da saúde, entendendo, principalmente, que um aumento do nível de práticas corporais da população contribui positivamente para a saúde e a qualidade de vida. Neste contexto, o que merece atençấo por parte daqueles que enveredam pelo campo da produção de conhecimento nesta temática é a resistência frente aos discursos hegemônicos das práticas corporais com fim nelas próprias, de modo a reforçar os valores pragmáticos e imediatistas no que se refere à $\mathrm{EF}$ como pertencente ao grande campo das Ciências da Saúde.

Embora a EF integre a grande área de Ciências da Saúde na Coordenação de Aperfeiçoamento de Pessoal de Nível Superior (CAPES), compreendemos ${ }^{3}$ que a sua oficialização como sendo uma das profissōes que compóem a cadeia de cuidados em saúde ocorreu com a Resolução 218/97 (BRASIL, 1997), iniciando assim uma aproximação latente com as políticas públicas de atenção à saúde. Em 1998, a Resolução 287 (BRASIL, 1998) relacionou a EF como uma das categorias profissionais de saúde de nível superior para fins de atuação no Conselho Nacional de Saúde. Em 2004, segundo as Diretrizes Curriculares Nacionais (DCN) dos cursos de EF, a formação deveria contemplar conteúdos referentes ao Sistema Único de Saúde - SUS (BRASIL, 2004). O mesmo teor também consta na nova DCN publicada em 2018 (BRASIL, 2018). Em 2006, o binômio "Práticas Corporais/Atividade Física” foi citado na Política Nacional de Promoção da Saúde (PNPS) (BRASIL, 2006). Em 2008 o profissional de EF passa a integrar as equipes do Núcleo de Apoio à Saúde da Família (NASF) (BRASIL, 2008). Em 2011 é criado o programa "Academia da Saúde", equipamento essencial para a prática de atividades físicas no SUS (BRASIL, 2011). Em 2013 a atividade física como um condicionante da saúde (BRASIL, 2013). Em nosso entendimento, esses são alguns dos marcos que selam, de vez, a EF no campo da saúde, que, até então, eram pontuais e isolados.

Ou seja, embora os enlaces venham se desenvolvendo desde o século XIX (SOUZA NETO et al., 2004), haja vista que os argumentos que legitimaram a construçáo do campo acadêmico da EF tiveram estreita ligação com o ideário higienista, somente há pouco mais de 20 anos a EF é considerada uma profissão da saúde. Soma-se a isso 
o fato de o SUS ser relativamente jovem, é possível compreender que a existência da EF no sistema de saúde oficial é recente, bem como de todos os seus desdobramentos, inclusive na produção de conhecimento numa perspectiva mais ampla. Ressaltamos ainda que é o SUS quem conclama a área para a atenção em saúde, demandando assim novas exigências formativas e de atuação profissional.

No que tange à saúde, seu conceito à luz da Organização Mundial da Saúde (OMS), como um estado de completo bem-estar físico, mental e social, e não somente a ausência de doença, não exprime o caráter dinâmico do processo de saúde (PALMA; ESTEVÃO; BAGRICHEVSKY, 2003). Os mesmos autores pontuam ainda que se trata da dificuldade de se alcançar um completo bem-estar, o que, para Segre e Ferraz (1997), torna-se irreal, ultrapassado e unilateral. Em contrapartida, a saúde sob um contexto ampliado, presente no contexto brasileiro desde 1986, por ocasião da realização da VIII Conferência Nacional de Saúde ${ }^{4}$, é aquela que transita numa compreensão que se alia à ideia multifacetada acerca dos determinantes sociais em saúde, conforme apontado por Buss e Pellegrini Filho (2007), desse modo, estando diretamente interligada ao pensamento de Minayo (1992; 2006), que afirma que a saúde é resultante das condiçôes de vida das pessoas.

Diante das transformaçóes pelas quais a EF tem passado ao longo de sua formação como campo científico e as diferentes concepçôes de saúde que surgem juntamente com a necessidade de humanizá-la, consideramos pertinente ampliar o entendimento sobre o que tem se produzido cientificamente a respeito do binômio EF e Saúde. Para tanto, o objetivo deste estudo consiste em entender e analisar a produção de conhecimento em EF e saúde em periódicos brasileiros.

Considerando que a EF passa a ser oficialmente reconhecida como pertencente à área da saúde; o profissional de EF é atuante no SUS, e que a saúde nos últimos anos tem sido discutida sob uma concepção mais ampla, o estudo sustenta como hipótese que o potencial de produção social de saúde do campo da EF já esteja repercutindo na produção acadêmica da área em questão.

\section{Método}

Para fins deste estudo, foi feita uma pesquisa bibliográfica que, segundo Gil (2008), é desenvolvida com base em material já elaborado, constituído principalmente de livros e artigos científicos. A abordagem utilizada foi a qualitativa, que, segundo 
Minayo (1994), responde a questôes muito particulares, preocupando-se com um nível de realidade que não pode ser quantificado. Nessa ótica, temos o pesquisador como elemento principal, o que, segundo Marconi e Lakatos (2010), é uma das características da abordagem qualitativa de pesquisa.

\section{Coleta de dados}

Para a coleta de dados, acessamos a base de dados LILACS. A busca se concentrou em periódicos que tinham como política editorial o livre acesso aos artigos. Os descritores utilizados foram: "educação física and saúde" e "physical education and health", haja vista que alguns periódicos nacionais permitem publicação na língua inglesa. O critério de seleção utilizado consistiu em publicaçôes realizadas a partir de 1997, considerando o reconhecimento da EF como profissão da área da Saúde por meio da Resoluçáo 218 (BRASIL, 1997). A busca foi realizada em junho de 2017 e considerou artigos publicados até o ano de 2016.

A busca inicial resultou em 1.622 artigos, aos quais aplicamos os seguintes critérios de exclusão:

- Artigos publicados em periódicos internacionais, haja vista que os periódicos brasileiros se configuram como objeto desse estudo;

- Artigos duplicados;

- Artigos que não continham nas palavras-chave os termos "Educação Física" e "Saúde" e/ou seus derivados (exemplo: EF Escolar, promoção da saúde, dentre outros).

- Textos de editorial;

- Artigos de revisão, com vistas à não duplicidade de resultados;

- Resenhas;

- Relatos de experiência, visto que não se trata de uma publicação comum na política editorial de revistas, o que dificultaria uma análise conjunta;

Nessa etapa, dois pesquisadores independentes procederam à avaliação, que, após aplicação dos critérios acima, chegou a uma amostra de 46 artigos (quadro 1), os quais foram lidos na íntegra: 
Quadiro 1. Seleção dos artigos*

\begin{tabular}{|c|c|}
\hline Amostra Inicial & 1.622 artigos \\
\hline Exclusão de artigos em periódicos internacionais & 1.193 \\
\hline Exclusão de artigos duplicados & 7 \\
\hline $\begin{array}{c}\text { Exclusão de artigos que não continham os termos "Educação } \\
\text { Física e Saúde" ou "Physical Education and Health" }\end{array}$ & 307 \\
\hline Exclusão de textos de editorial & 0 \\
\hline Exclusão de artigos de revisão & 11 \\
\hline Exclusão de resenhas & 0 \\
\hline Exclusão de artigos de relato de experiência & 58 \\
\hline Total de exclusões & 1.576 \\
\hline Amostra final & 46 \\
\hline
\end{tabular}

Fonte: dados da pesquisa.

*A seleção dos artigos obedeceu à ordem descrita na ilustração.

\section{Análise dos dados}

Baseado em Oliveira et al. (2017), os dados foram analisados a partir dos seguintes aspectos:

1. Periódicos, ano de publicação e sua respectiva avaliação no sistema Qualis Capes: a avaliação da produção científica por esse sistema possui influência na produção de conhecimento e sua respectiva disseminação (MARCHLEWSKI, SILVA e SORIANO, 2011). Para fins desse estudo, foi considerada a avaliação na área da EF, haja vista especificidade da temática. Entretanto, considerou-se ainda a avaliação na área interdisciplinar, pois segundo Bracht (2000), a EF tem uma natureza científica diversa e com fronteiras em constante expansão, bem como seu objeto de estudo (movimentar-se humano) perpassa várias áreas do conhecimento;

2. Tipo do estudo: objetivou-se visualizar as características textuais da produção acadêmica. A classificação adotada neste estudo é a seguinte: artigo original - é aquele fruto de uma pesquisa científica e que possui dados originais - e ensaios - artigos que promovem reflexóes sobre uma temática, se valendo ou não de dados empíricos; 
3. Abordagem metodológica: qualitativa, quantitativa ou mista;

4. Instrumento de coleta de dados: evidenciar quais são as ferramentas metodológicas mais usuais, à medida que estes acabam por revelar não só como se deu a aproximação com os dados, mas como esse processo foi construído;

5. Amostragem metodológica: seres humanos (pesquisa desenvolvida com dados diretos ou indiretos de seres humanos, obedecendo aos preceitos da Resolução n. 466/2012 (BRASIL, 2012) e 196/96 (BRASIL, 1996), documentos (material impresso e/ou eletrônico produzido por pessoas e/ou instituiçôes) e/ ou mistos;

6. Temáticas abordadas: feitas por categorias não apriorísticas, que, para Campos (2004), surgem no contato com o material analisado. No caso desse estudo, foi considerada a principal variável analisada pelos estudos;

7. Área de diálogo com o conhecimento: Ciências Humanas ou Ciências Naturais;

8. Conceito de saúde empregado no texto: idem item 6.

\section{Resultados}

No que se refere aos periódicos, ano de publicação e sua respectiva avaliação no sistema Qualis Capes, o quadro 2 mostra que os 46 artigos foram publicados em 23 periódicos. Considerando os estratos de avaliação (A1, A2, B1, B2, B3, B4, B5 e C) na área da EF, os periódicos transitam entre A2 e B4, e o maior número de publicaçóes está na esfera B1 (5 artigos). Entretanto, considerando a avaliação na área Interdisciplinar, os periódicos transitam entre A1 e B4, ainda com maior número de publicaçôes na esfera B1, dessa vez com 11 publicaçóes. Nota-se que o maior número de artigos publicados (41) se dá após 10 anos (a partir de 2008) de efetiva indução das políticas públicas de saúde na direção da EF. Entre 1997 e 2007 apenas 5 artigos foram publicados. 
Quadro 2. Periódicos, ano de publicação e sua avaliação no sistema Qualis Capes

\begin{tabular}{|c|c|c|c|c|}
\hline Autoria & Revistas & $\begin{array}{c}\text { Avaliação do } \\
\text { sistema Qualis } \\
\text { Capes Educação } \\
\text { Física }\end{array}$ & $\begin{array}{c}\text { Avaliação } \\
\text { do sistema } \\
\text { Qualis Capes } \\
\text { Interdisciplinar }\end{array}$ & $\begin{array}{c}\text { Quantidade } \\
\text { de artigos } \\
\text { publicados }\end{array}$ \\
\hline $\begin{array}{l}\text { Penteado, Silva e } \\
\text { Montebello (2015) }\end{array}$ & Codas & B1 & B1 & 1 \\
\hline $\begin{array}{c}\text { Penteado e Silva } \\
\text { (2014), Penteado et } \\
\text { al. (2015) }\end{array}$ & $\begin{array}{l}\text { Distúrbios da } \\
\text { Comunicação }\end{array}$ & B2 & B3 & 2 \\
\hline $\begin{array}{l}\text { Mendes e Nóbrega } \\
\text { (2008), Melo e } \\
\text { Peres (2016) }\end{array}$ & $\begin{array}{c}\text { História, } \\
\text { Ciências, Saúde - } \\
\text { Manguinhos }\end{array}$ & Sem avaliação & $\mathrm{A} 1$ & 2 \\
\hline $\begin{array}{c}\text { Cunha Júnior } \\
\text { (2009) }\end{array}$ & HU Revista & B4 & Sem avaliação & 1 \\
\hline $\begin{array}{l}\text { Roble, Moreira e } \\
\text { Scagliusi (2012), } \\
\text { Lüdorf e Ortega } \\
\text { (2013), Falci e } \\
\text { Belisário (2013) }\end{array}$ & $\begin{array}{c}\text { Interface: } \\
\text { Comunicação, } \\
\text { Saúde e Educação }\end{array}$ & B2 & A2 & 3 \\
\hline $\begin{array}{l}\text { Souza e Costa } \\
\text { (2011) }\end{array}$ & $\begin{array}{c}\text { Jornal Brasileiro de } \\
\text { Psiquiatria }\end{array}$ & B3 & B1 & 1 \\
\hline $\begin{array}{l}\text { Legnani et al. } \\
(2012) \text {, Finco } \\
\text { e Fraga (2012), } \\
\text { Ennis (2013 }\end{array}$ & Motriz & B1 & B1 & 3 \\
\hline $\begin{array}{l}\text { Minelli, Soriano } \\
\text { e Fávaro (2009), } \\
\text { Pedrosa e Leal } \\
\text { (2012), Furtado } \\
\text { et al. (2015), } \\
\text { Santiago, Pedrosa e } \\
\text { Ferraz (2016) }\end{array}$ & Movimento & A2 & B1 & 4 \\
\hline Brito et al. (2012) & Pediatria Moderna & B4 & B4 & 1 \\
\hline Abib et al. (2010) & Pensar a Prática & B2 & B2 & 1 \\
\hline
\end{tabular}

continua... 


\begin{tabular}{|c|c|c|c|c|}
\hline Autoria & Revistas & $\begin{array}{c}\text { Avaliação do } \\
\text { sistema Qualis } \\
\text { Capes Educação } \\
\text { Física }\end{array}$ & $\begin{array}{c}\text { Avaliação } \\
\text { do sistema } \\
\text { Qualis Capes } \\
\text { Interdisciplinar }\end{array}$ & $\begin{array}{c}\text { Quantidade } \\
\text { de artigos } \\
\text { publicados }\end{array}$ \\
\hline $\begin{array}{c}\text { Brugnerotto e } \\
\text { Simóes (2009), } \\
\text { Anjos e Duarte } \\
\quad(2009)\end{array}$ & Physis & B2 & B1 & 2 \\
\hline $\begin{array}{l}\text { Moraes et al. } \\
\text { (2009) }\end{array}$ & $\begin{array}{c}\text { Revista da } \\
\text { Associação Médica } \\
\text { Brasileira }\end{array}$ & B2 & B2 & 1 \\
\hline $\begin{array}{l}\text { Franco, Gonçalves } \\
\text { e Padovani (2009) }\end{array}$ & $\begin{array}{c}\text { Revista Brasileira de } \\
\text { Medicina }\end{array}$ & B3 & B3 & 1 \\
\hline $\begin{array}{l}\text { Farias Júnior et al. } \\
\qquad(2012)\end{array}$ & $\begin{array}{c}\text { Revista de Saúde } \\
\text { Pública }\end{array}$ & A2 & B1 & 1 \\
\hline $\begin{array}{c}\text { Ferreira et al. } \\
\text { (2006), Santos e } \\
\text { Benedetti (2012), } \\
\text { Sá e Florindo } \\
\text { (2012), Silva (2012), } \\
\text { Barros et al. (2013), } \\
\text { Xavier e Knuth } \\
\text { (2016), Colantonio } \\
\text { et al. (1999) }\end{array}$ & $\begin{array}{c}\text { Revista Brasileira } \\
\text { de Atividade Física } \\
\text { e Saúde }\end{array}$ & B2 & B4 & 7 \\
\hline $\begin{array}{l}\text { Mohr, Guimarães } \\
\text { e Barbosa (2011), } \\
\text { Freitas et al.(2011), } \\
\text { Silva et al. (2012), } \\
\text { Ferreira, Oliveira } \\
\text { e Sampaio (2013), } \\
\text { Alberto e Figueira } \\
\text { Júnior (2016) }\end{array}$ & $\begin{array}{l}\text { Revista Brasileira de } \\
\text { Ciências do Esporte }\end{array}$ & B1 & B1 & 5 \\
\hline $\begin{array}{l}\text { Guedes, Santos } \\
\text { e Lopes (2006), } \\
\text { Santos et al. (2015), } \\
\text { Madureira, Fonseca } \\
\text { e Maia (2003) }\end{array}$ & $\begin{array}{l}\text { Revista Brasileira de } \\
\text { Cineantropometria } \\
\text { e Desempenho } \\
\text { Humano }\end{array}$ & B1 & Sem avaliação & 3 \\
\hline
\end{tabular}




\begin{tabular}{|c|c|c|c|c|}
\hline Autoria & Revistas & $\begin{array}{c}\text { Avaliação do } \\
\text { sistema Qualis } \\
\text { Capes Educaçáo } \\
\text { Física }\end{array}$ & $\begin{array}{c}\text { Avaliação } \\
\text { do sistema } \\
\text { Qualis Capes } \\
\text { Interdisciplinar }\end{array}$ & $\begin{array}{l}\text { Quantidade } \\
\text { de artigos } \\
\text { publicados }\end{array}$ \\
\hline $\begin{array}{l}\text { Schubert et al. } \\
\qquad(2016)\end{array}$ & $\begin{array}{c}\text { Revista Brasileira } \\
\text { de Medicina do } \\
\text { Esporte }\end{array}$ & A2 & B1 & 1 \\
\hline $\begin{array}{c}\text { Oliveira, Martins e } \\
\text { Bracht (2015) }\end{array}$ & $\begin{array}{c}\text { Revista de } \\
\text { Educação Física } \\
\text { (UEM) }\end{array}$ & B1 & B1 & 1 \\
\hline $\begin{array}{l}\text { Gouvêa e Lopes } \\
\text { (2007) }\end{array}$ & $\begin{array}{l}\text { Revista do Instituto } \\
\text { de Ciências da } \\
\text { Saúde (UNIP) }\end{array}$ & B4 & B4 & 1 \\
\hline $\begin{array}{l}\text { Pacheco, Tirintan } \\
\text { e Oliveira (2016) }\end{array}$ & Salusvita & B4 & B4 & 1 \\
\hline Carvalho (2009) & Saúde e Sociedade & A2 & B1 & 1 \\
\hline \multirow[t]{2}{*}{$\begin{array}{l}\text { Saporetti, Miranda } \\
\text { e Belisário (2016), } \\
\text { Almeida, Heckert e } \\
\text { Barros (2011) }\end{array}$} & $\begin{array}{c}\text { Trabalho, educação } \\
\text { e saúde }\end{array}$ & B2 & B1 & 3 \\
\hline & TOTAL & & & 46 \\
\hline
\end{tabular}

Fonte: dados da pesquisa.

No que tange ao tipo de estudo, observou-se predominância de artigos originais, como mostra o quadro 3 .

Quadro 3. Tipo de estudo

\begin{tabular}{|c|c|}
\hline Tipo & Quantidade de artigos \\
\hline Artigos originais & 39 \\
\hline Ensaios & 7 \\
\hline TOTAL & 46 \\
\hline
\end{tabular}

Fonte: dados da pesquisa. 
No que se refere à abordagem metodológica, foi possível observar a predominância da natureza quantitativa (19 artigos) de pesquisa amparada nos seguintes instrumentos de coleta de dados: questionários validados nacional ou internacionalmente (10 estudos); questionários não validados (4 estudos); análise de conteúdo (1 estudo) e avaliação física (5 estudos). Foram encontrados 15 estudos qualitativos sustentados por instrumentos de coleta de dados clássicos dessa vertente científica, tais como: questionário aberto (2 estudos); observação participante (5 estudos); observação não participante (1 estudo); entrevista semiestruturada (11 estudos); entrevistas estruturadas (2 estudos); grupo focal (3 estudos), e; análise de conteúdo (4 estudos). Houve ainda a ocorrência de 3 estudos mistos (quali-quantitativos) que se valeram de análise de conteúdo (1 estudo), questionários validados (2 estudos) e não validado (1 estudo) ${ }^{5}$. É válido ressaltar que, para a avaliação dos instrumentos de coleta de dados, os ensaios foram excluídos.

No que se refere à amostragem metodológica, foi possível observar a predominância de estudos provenientes de dados diretos e/ou indiretos de seres humanos (35), ao passo que 11 estudos foram desenvolvidos a partir de documentos impressos ou publicados em sítios eletrônicos.

Em relação às temáticas abordadas nos estudos, foi possível listar 15 (quadro 4), destacando-se a temática da atuação profissional.

Quadiro 4. Temáticas abordadas

\begin{tabular}{|c|c|c|}
\hline & Tema & Frequência \\
\hline 1 & Atuação profissional* & 13 \\
\hline 2 & Estilo de vida & 7 \\
\hline 3 & Atividade física & 6 \\
\hline 4 & Formação profissional & 5 \\
\hline 5 & Educação física escolar & 3 \\
\hline 6 & Saúde vocal & 3 \\
\hline 7 & Saúde do trabalhador & 2 \\
\hline 8 & Saúde mental & 2 \\
\hline 9 & Corpo e saúde & 1 \\
\hline
\end{tabular}

continua... 


\begin{tabular}{|c|c|c|}
\hline & Tema & Frequência \\
\hline 10 & Ginástica & 1 \\
\hline 11 & Produção de conhecimento & 1 \\
\hline 12 & Jogos eletrônicos & 1 \\
\hline 13 & Qualidade de vida & 1 \\
\hline 14 & Treinamento esportivo & 1 \\
\hline 15 & Transtorno alimentar/Imagem corporal & 1 \\
\hline
\end{tabular}

Fonte: dados da pesquisa.

*Dois estudos abordaram a temática da atuação profissional conjuntamente com a formação profissional e foram computadas nas duas categorias.

Nesse contexto, é válido ressaltar que embora as práticas corporais não tenham surgido como temáticas dos estudos, foram abordadas como conceito em nove manuscritos - todos oriundos das Ciências Humanas. Outra ressalva que fazemos é sobre a cultura corporal não figurar como temática, um termo táo caro à área que se desenvolveu na década de 1990 a partir da publicação do Coletivo de Autores (1992). Entretanto, foi abordada em 6 estudos também com matriz teórica nas Ciências Humanas.

No que diz respeito à área de diálogo, 26 artigos estão sob a matriz das Ciências Humanas e 20 das Ciências Naturais. Para fins desse estudo, todos os trabalhos de matriz epistemológica calcados nas análises biológicas, físicas e químicas foram considerados da área das Ciências Naturais. Ao passo que nas Ciências Humanas foram considerados os trabalhos embasados em análises filosóficas, antropológicas, históricas, sociológicas, pedagógicas, psicológicas e linguísticas.

Por fim, quanto ao conceito de saúde, 17 estudos se aproximaram da concepçáo ampliada, considerada aqui como toda discussão teórica que se distanciasse da perspectiva de saúde da OMS. Nesse sentido, se aproximaram ou assumiram o conceito de saúde resultante da VIII Conferência Nacional de Saúde de 1986.

Nos 29 estudos restantes, o conceito de saúde não foi citado/discutido/mencionado em 26 deles, dentre os quais 17 dialogando com as Ciências Naturais e nove com as Ciências Humanas. Outros três estudos esboçaram um conceito de saúde restrito à aptidão física, na qual a argumentação teórica se fundamentou na perspectiva da funcionalidade do organismo em desempenhar tarefas físicas e/ou motoras. 


\section{Discussão}

A produção de conhecimento em EF e Saúde em periódicos brasileiros tem sido alvo de discussão quase que exclusivamente de pesquisadores brasileiros, com exceção do estudo de uma pesquisadora norte-americana - Ennis (2013). Numa primeira análise, o dado contraria a tendência dos periódicos brasileiros de internacionalizar suas publicaçóes, como, por exemplo, possibilitar submissóes em inglês e espanhol ou, no caso da Revista Motriz, adotar apenas a língua inglesa em suas submissões, o que não é um ditame apenas para os periódicos da EF. Em Avena e Barbosa (2018), que avaliaram periódicos brasileiros de Enfermagem indexados no Scielo em comparação a revistas internacionais com fator de impacto entre 1 e 1,8, é possível compreender que a internacionalização das publicações é uma demanda contemporânea que urge na ciência brasileira. Por outro lado, os dados da pesquisa de Carbinatto et al. (2016), que investigaram a produção de conhecimento em ginástica nos periódicos brasileiros, mostraram uma diminuição do quantitativo de publicaçóes a partir de 2010. Para os autores, isso pode ser explicado pela "[...] busca da internacionalização das pesquisas”. Para tanto, Carbinatto et al. (2016), apoiados em Andrade et al. (2013), mostraram o aumento exponencial de publicaçôes de pesquisadores brasileiros em revistas internacionais no quinquênio 2008-2012 (1.665) em comparação ao período de 2003-2007 (260). Embora nosso estudo demonstre que as publicações não diminuíram a partir de 2010, é fato que a internacionalização dos periódicos e das pesquisas produz efeitos diversos na produção de conhecimento em periódicos brasileiros. Isso deixa o cenário de publicaçóes nacionais como alvo privilegiado de pesquisadores locais, uma vez que os fatores de impacto das revistas não são atrativos para o mundo. Padilha et al. (2014) afirmam que esse é o desafio: atrair pesquisadores estrangeiros para as revistas nacionais, ora fomentando o cenário de publicações internacionais, sendo este de maior visibilidade e reconhecimento acadêmico. Para os autores, o encorajamento da internacionalização dos periódicos passa por essas razóes. Entretanto, faz-se necessário admitir que esse é um limite do estudo, pois não buscamos investigar a produção em outras áreas de avaliação da Capes (somente EF e Interdisciplinar), bem como não se avaliaram os periódicos internacionais. Sem dúvida, esse seria um fator que, potencialmente, aumentaria o número de publicaçôes para além do que fora encontrado nesse estudo. 
Por outro lado, sendo a atuação do profissional de EF a temática mais frequente dentre os estudos analisados, os dados encontram coerência, pois desde que a EF passa a ser considerada uma profissão da saúde, em 1997, consequentemente inserida em fóruns específicos do setor, entende-se que a comunidade científica é demandada a compreender o fenômeno. Nesse contexto, não avaliamos como coincidência que o maior número de publicaçóes tenha se dado após 2008, pois se entende que entre 1997 e 2006, várias foram as políticas de cuidado em saúde criadas que abarcaram a área da EF, com destaque para a PNPS (BRASIL, 2006).

Em relação ao Qualis Capes da EF, os dados do estudo demonstram que os artigos estão concentrados nos estratos B1 e B2 (5 e 7 estudos, respectivamente), sem nenhum no estrato máximo (A1), e 4 deles em A2. Estando os programas de pósgraduação brasileiros cada vez mais exigentes quanto às publicaçôes de orientadores e orientandos nos estratos superiores (A1 e A2), pode-se inferir que a temática ainda não possui impacto na pós-graduação ou há uma desvalorização desse nicho de conhecimento. Embora Barata (2016) afirme que o Qualis não avalia a qualidade da publicação, uma vez que sua existência se deve a avaliar programas de pós-graduação, e não uma ferramenta para avaliar o desempenho científico dos pesquisadores, os dados deste estudo podem representar um alerta para a produção de conhecimento na temática. Entretanto, caso seja considerado o Qualis Capes da área Interdisciplinar, o panorama é outro, pois os artigos se concentram em B1 (11 estudos), já sendo possível visualizar 1 artigo no estrato máximo e outro em A2. Com todas as ressalvas existentes, cabe aqui a compreensão que a temática (EF e Saúde) tem sido mais bem acolhida na perspectiva Interdisciplinar, bem como demonstra uma contribuição da EF em áreas que superam as Ciências da Saúde (área original na Capes).

Por fim, vale ressaltar que a utilização do Qualis como um item avaliativo numa revisão sistemática como esta, mesmo questionável, é pertinente a caracterização da amostra, bem como por ser uma métrica recorrente em outras revisôes em áreas distintas, a exemplo de Polippo (2016) e Guedes e Tada (2015).

No que tange ao tipo de estudo e abordagem metodológica, já era esperado a predominância de artigos originais de natureza quantitativa. Embora a EF tenha incorporado os referenciais das Ciências Humanas em sua produção científica desde a década de 1980, as vertentes da aptidão e avaliação física associadas ao comportamento físico frente a um parâmetro de saúde se fazem muito presentes. Segundo Silva (2005), a produção científica da área em seu início de diálogo com 
a ciência (final da década de 1970 até meados da década de 1980) gravitava em torno do esporte profissional, da avaliação da aptidáo física e de aspectos médicobiológicos da atividade física, sendo a abordagem quantitativa predominante. Não se trata aqui de uma crítica a estudos dessa natureza, mas apenas a constatação, corroborada há quase 20 anos atrás em Bracht (2000), de que a EF ainda é um campo científico em constituição e com fronteiras móveis. Nessa perspectiva, defende-se que a área se reconheça como diversa e que a discussão sobre a saúde possa se valer de diferentes correntes teórico-metodológicas para produzir conhecimento, fugindo sempre de nichos específicos.

Nessa ótica, a existência de 15 temáticas diversas abordadas entre 1999 e 2016 demonstra que essa trilha já tem sido percorrida pelos pesquisadores brasileiros. Embora a temática mais frequente seja a atuação profissional (13 estudos), demonstrando o esforço da área em busca do entendimento da intervenção e do papel do profissional de EF no setor da Saúde, o estilo de vida (7 estudos), a atividade física (6 estudos) e a formação profissional (5 estudos) acabam por revelar um balizamento da produção de conhecimento com a sociedade contemporânea. $\mathrm{Na}$ atualidade, a população tem sido alvo de uma verdadeira enxurrada de recomendaçôes, as quais envolvem mudança no estilo de vida pela adoção de práticas ditas saudáveis, como, por exemplo, aderir a uma prática corporal. Tais premissas esbarram nos limites socioculturais que, na ótica de Carvalho (2001), têm sido secundarizados nas análises que envolvem a atividade física.

Assim, é possível inferir que há forte tendência da produção de conhecimento em EF e Saúde para compreender a intervenção do profissional nas demandas contemporâneas que cercam o estilo de vida ativo, usando um termo de Fraga (2006), que envolve a atividade física, bem como as demandas desse contexto para a formação universitária. Nesse ínterim, destaca-se o uso dos termos "práticas corporais" e "cultura corporal" no contexto exclusivo de estudos oriundos das Ciências Humanas, o que reforça a ideia de que esse é um contraponto da área à perspectiva da atividade física ligada aos estudos com matriz nas Ciências Naturais.

Em relação ao conceito de saúde, os dados revelam uma preocupação: o fato de 26 estudos não a conceituarem. Não fazê-lo pode significar que o termo, por si só, está dado e é de conhecimento universal. Entretanto, sabe-se que o conceito de saúde é um terreno polissêmico e passível de diversas abordagens, o que nos permite afirmar, ao lado de Pacheco, Tirintan e Oliveira (2016), que um conceito de saúde circunscrito 
numa perspectiva mais ampla avança na compreensão da saúde como ausência de doença ou como completo bem-estar físico, psíquico e social. Nesse sentido, seria importante que artigos publicados em periódicos pudessem mencionar a concepção de saúde. Caso contrário, corre-se o risco da saúde, numa área como a EF, se consolidar como restrita à aptidáo física, como foi o caso de 3 estudos analisados. $\mathrm{O}$ fator de preocupação não é a existência dessa perspectiva, mas esta se tornar hegemônica, justamente pela não discussão científica. Por outro lado, é compreensível que estudos publicados em periódicos, por limites de caracteres/palavras, não consigam discutir outros desdobramentos e necessitem de uma edição mais rigorosa do texto, excluindo a possibilidade de se posicionar sobre o conceito de saúde.

Entretanto, a existência de 17 estudos que discorreram sobre o conceito de saúde numa perspectiva ampliada acabou por apontar uma tendência dentre os pesquisadores: a de compreender a saúde como uma experimentação do indivíduo em sua relação com a sociedade (PALMA; ESTEVÃO; BAGRICHEVSKY, 2003). Isso significa um alinhamento com as políticas públicas de produção de cuidado em saúde, bem como uma compreensão de saúde que extrapola o universo das práticas corporais, mas também considera outros fatores.

\section{Conclusão}

A produção de conhecimento em EF e saúde no Brasil entre 1997 e 2016 se mostrou dinâmica e ampla em termos de temática. Dado o reconhecimento da EF como integrante do campo das Ciências da Saúde, aquilo que se observou foi a multiplicidade de olhares e escopos de pesquisa no que tange à produção do conhecimento ora elencada. Nessa esteira, a variedade de abordagens metodológicas, bem como as diferentes linhas de entendimento sobre o binômio práticas corporais e saúde, revela o quanto a interdisciplinaridade está presente na produção científica da EF.

Isso posto, a hipótese acerca de a produção científica na área ir além da visão biomédica para o conceito de saúde foi confirmada, levando-nos a acreditar que a EF e a saúde gravitam de forma interdisciplinar e multifocal no que se refere à riqueza de metodologias e açóes empregadas na prática dos profissionais de EF.

A presença expressiva de artigos sobre a atuação profissional da EF na saúde e/ou formação acadêmica em EF para o trabalho em saúde nos permitem compreender 
que os direcionamentos à produção social de saúde repercutem na produção acadêmica da área. Embora o entendimento sobre o "fenômeno" saúde não seja predominantemente tomado sob a perspectiva ampliada, a formação e a atuação em saúde por parte da EF são, ao menos, objetos de dúvida e interesse por parte dos pesquisadores, apontando para a necessidade de reflexão sobre o assunto.

Por fim, espera-se que, com o constante avançar da ciência, as frentes de entendimento sobre EF e saúde possam continuar a desenvolver-se e ampliar-se, não em um movimento de exclusão, mas sim no horizonte do entrelaçamento de conhecimentos, sendo frutífero para a EF contextualizar-se cada vez mais com as demandas do setor saúde. ${ }^{6}$

\section{Referências}

ABIB, L. T. et al. Práticas corporais em cena na saúde mental: potencialidades de uma oficina de futebol em um Centro de Atenção Psicossocial de Porto Alegre. Pensar a Prática, v.13, n.2, p.1-15, 2010.

ALBERTO, A. A. D.; FIGUEIRA JÚNIOR, A. J. F. Percepçóes de determinantes bioculturais da atividade física e associação com características pessoais e profissionais de professores de Educação Física. Revista Brasileira de Ciências do Esporte, v. 38, n. 3, p. 275-282, 2016.

ALMEIDA, U. R.; HECKERT, A. L. C.; BARROS, M. E. B. Nas trilhas da atividade: análise da relação saúde-trabalho de uma professora de educação física escolar. Trabalho, Educação e Saúde, v. 9, sup. 1, p. 245-263, 2011.

ANDRADE, D. et al. Bibliometric analysis of South American research in sports science from 1970 to 2012. Motriz, v. 19, n. 4, p. 783-791, 2013.

ANJOS, T. C.; DUARTE, A. C. G. O. A Educação Física e a Estratégia de Saúde da Família: formação e atuação profissional. Physis, v. 19, n. 4, p. 1127-1144, 2009.

AVENA, M. J.; BARBOSA, D. A. Brazilian nursing journals: strengths, weaknesses and challenges. Revista Brasileira de Enfermagem, v. 71, n. 5, p. 2489-2495, 2018.

BARATA, R. C. B. Dez coisas que você deveria saber sobre o Qualis. Revista Brasileira de Pósgraduação, v. 13, n. 30, p. 13-40, 2016.

BARROS, S. S. H. et al. Aulas de Educação Física e indicadores de violência em adolescentes. Revista Brasileira de Atividade Física e Saúde, v. 18, n. 5, p. 566-575, 2013.

BRACHT, V. Identidade e Crise da Educação Física: um enfoque epistemológico. In: BRACHT, V. CRISÓRIO, R (Orgs.). A Educação Física no Brasil e na Argentina. Campinas: Autores Associados, 2003. p. 13-29. 
BRACHT, V. A constituição das teorias pedagógicas da educação física. Cadernos Cedes, s/v, n.48, p.69-88, 1999.

. Educação Física \& Ciência: cenas de um casamento (in)feliz. Revista Brasileira de Ciências do Esporte, Campinas, v.22, n.1, p.53-63, set./dez., 2000.

BRASIL. Casa Civil. Lei n. 12.864. Brasília: Casa Civil, 2013.

. Ministério da Educação. Conselho Nacional de Educação. Resolução CNE/CP n. 218. Brasília: MEC, 1997.

. Ministério da Educação. Conselho Nacional de Educação. Resolução CNE/CP n. 7. Brasília: MEC, 2004.

. Ministério da Educação. Conselho Nacional de Educação. Resoluçâo CNE/CP n. 287. Brasília: MEC, 1998.

. Ministério da Educação. Conselho Nacional de Educação. Resolução CNE/CP n. 6. Brasília: MEC, 2018.

. Ministério da Saúde. Conselho Nacional de Saúde. Resolução 196. Brasília: MS, 1996. . Ministério da Saúde. Conselho Nacional de Saúde. Resolução 466. Brasília: MS, 2012. . Ministério da Saúde. Portaria n. 154. Brasília: MS, 2008.

_. Ministério da Saúde. Portaria n. 687. Brasília: MS, 2006.

. Ministério da Saúde. Portaria n. 719. Brasília: MS, 2011.

. Ministério da Saúde. VIII Conferência Nacional de Saúde. 1986. Relatório Final. Brasília: MS, 1986.

BRITO, A. K. A. et al. Efeitos de uma intervenção na educação física escolar, sobre parâmetros relacionados à saúde, em escolares - estudo piloto. Pediatria Moderna, v. 48, n. 1. p. 461-467, 2012.

BRUGNEROTTO, F.; SIMÔES, R. Caracterização dos currículos de formação profissional em Educação Física: um enfoque sobre saúde. Physis, v. 19, n. 1, p. 149-172, 2009.

BUSS, P. M.; PELEGRINI FILHO, A. A saúde e seus determinantes sociais. Physis, v. 17, n. 1, p. 77-93, 2007.

CAMPOS, J. G. C. Método de análise de conteúdo: ferramenta para a análise de dados qualitativos no campo da saúde. Revista Brasileira de Enfermagem, v. 5, n. 57, p. 611-614, 2004.

CARBINATTO, M. V. et. al. Produção de conhecimento em Ginástica: uma análise a partir dos periódicos brasileiros. Movimento, v. 22, n. 4, p. 1293-1308, 2016.

CARVAlHO, F. F. B. Análise crítica da Carta Brasileira de Prevenção Integrada na Área da Saúde na perspectiva da Educação Física através do enfoque radical de Promoção da Saúde. Saúde e Sociedade, v. 18, n. 2, p. 227-236, 2009. 
CARVALHO, Y. M. Atividade física e saúde: onde está e quem é o "sujeito" da relação? Revista Brasileira de Ciências do Esporte, v.22, n.2, p.9-21, 2001.

COLANTONIO, E. et al. Avaliação do crescimento e desempenho físico de crianças e adolescentes. Revista Brasileira de Atividade Física e Saúde, v.4, n.2, p.17-29, 1999.

COLETIVO DE AUTORES. Metodologia do ensino da Educação Física. São Paulo: Cortez, 1992.

CUNHA JÚNIOR, C. F. F. Uma história da relação entre saúde e educação física na educação brasileira. HU Revista, v. 35, n. 3, p. 227-234, 2009.

DAOLIO, J. Educação Física Brasileira: autores e atores da década de 1980. Campinas: Papirus, 1998.

ENNIS, C. D. Reimagining professional competence in physical education. Motriz, v. 19, n. 4, p. 662-672, 2013.

FARIAS JÚNIOR, J. C. et al. Prática de atividade física e fatores associados em adolescentes no Nordeste do Brasil. Revista de Saúde Pública, v. 46, n. 3, p. 505-515, 2012.

FERON, A.; SILVA, M. A igreja do “diabo" e a produção do conhecimento na educação física. Revista Brasileira de Ciências do Esporte, Porto Alegre, v. 29, n. 1, p. 107-122, 2007.

FERREIRA, H. S.; OLIVEIRA, B. N.; SAMPAIO, J. J. C. Análise da percepção dos professores de educação física acerca da interface entre a saúde e a educação física escolar: conceitos e metodologias. Revista Brasileira de Ciências do Esporte, v. 35, n. 3, p. 673-685, 2013.

FERREIRA, P.L. et al. Avaliação da saúde, fatores de risco e estado nutricional de crianças e adultos frequentadores de um programa de natação. Revista Brasileira de Atividade Física e Saúde, v. 11, n. 3, p. 23-31, 2006.

FINCO, M.D.; FRAGA, A.B. Rompendo fronteiras na Educação Física através dos videogames com interação corporal. Motriz, v. 18, n. 3, p.533-541, 2012.

FRAGA, A.B. Promoção da vida ativa: nova ordem físico-sanitária na educação dos corpos contemporâneos. In: BAGRICHEVSKY, M. et al. A saúde em debate na educação física. vol.2. Blumenau: Nova Letra, 2006. p. 105-120.

FRANCO, A. C. S. F.; GONÇALVES, A.; PADOVANI, C. R. Absence motivated by illness: a non-concurrent prospective study of physical education teachers in the municipal education system of the city of Campinas, São Paulo, Brazil. Revista Brasileira de Medicina, v. 66, n. 9, p. 286-290, 2009.

FREITAS, D.C. et al. As práticas corporais nas academias de ginástica: um olhar do professor sobre o corpo fluminense. Revista Brasileira de Ciências do Esporte, v. 33, n. 4, p. 959-974, 2011. FURTADO, R.P. et al. O trabalho do professor de Educação Física no Caps: aproximaçóes iniciais. Movimento, v. 21, n. 1, p. 41-52, 2015.

GIL, A. C. Como elaborar projetos de pesquisa. 4. ed. São Paulo: Atlas, 2008. 
GOUVÊA, F. S.; LOPES, M. B. S. Análise das ações de distribuição ofensiva (levantamentos) no Voleibol Infanto-Juvenil feminino. Revista do Instituto de Ciências da Saúde, v. 25, n. 4, p. 337-344, 2007.

GUEDES, D. P.; SANTOS, C. A.; LOPES, C. C. Estágios de mudança de comportamento e prática habitual de atividade física em universitários. Revista Brasileira de Cineantropometria e Desempenho Humano, v. 8, n. 4, p. 5-15, 2006.

GUEDES, N. P. S.; TADA, I. N. C. A produção científica brasileira sobre autismo na Psicologia e na Educação. Psicologia: teoria e pesquisa, v. 31, n. 3, p. 303-309, 2015.

KUNZ, E. Ministério da Saúde Adverte: viver é prejudicial à saúde. In: BAGRICHEVSKY, M.; ESTEVÃO, A.; PALMA, A. (Orgs.). A saúde em debate na educação física. Vol.3. Ilhéus: Editus, 2007. p. 173-186.

LAZZAROTTI FILHO, A. et. al. O termo práticas corporais na literatura científica brasileira e sua repercussão no campo da Educação Física. Movimento, v. 16, n. 1 p. 11-29, jan. /mar. 2010.

LEGNANI, R. F. S. et al. Transtornos alimentares e imagem corporal em acadêmicos de Educação Física. Motriz, v. 18, n. 1, p. 84-91, 2012.

LÜDORF, S. M. A.; ORTEGA, F. J. G. Marcas no corpo, cansaço e experiência: nuances do envelhecer como professor de Educação Física. Interface, v. 17, n. 46, p. 661-75, 2013.

MADUREIRA, A. S.; FONSECA, S. A.; MAIA, M. F. M. Estilo de vida e atividade física habitual de professores de Educação Física. Revista Brasileira de Cineantropometria de Desempenho Humano, v.5, n. 1, p. 54-62, 2003.

MARCHLEWSKI, C.; SILVA, P. M.; SORIANO, J. B. A influência do sistema de avaliação Qualis na produção de conhecimento científico: algumas reflexôes sobre a Educação Física. Motriz, v. 17, n. 1, p. 104-116, 2011.

MARCONI, M.A.; LAKATOS, E.M. Fundamentos de Metodologia Científica. 7.ed. São Paulo: Atlas, 2010.

MELO, V. A.; PERES, F. F. Relaçôes entre ginástica e saúde no Rio de Janeiro do século XIX: reflexóes a partir do caso do Colégio Abílio, 1872-1888. História, Ciências, Saúde - Manguinhos, v. 23, n. 4, p. 1133-1151, 2016.

MENDES, M. I. B. S.; NÓBREGA, T. P. O Brazil-Medico e as contribuições do pensamento médico-higienista para as bases científicas da Educação Física brasileira. História, Ciências, Saúde-Manguinhos, v. 15, n. 1, p. 209-219, 2008.

MINAYO, M. C. S. (Org.). Pesquisa social: teoria, método e criatividade. 9.ed. Petrópolis: Vozes, 1994.

. A saúde em estado de choque. Rio de Janeiro: Espaço e Tempo, 1992. 
- Saúde como responsabilidade cidadã. In: BAGRICHEVSKY, M.; PALMA, A.; ESTEVĀO, A. (Orgs.). A Saúde em Debate na Educação Física. V. 2. Blumenau: Nova Letra, 2006. p. 93-102.

MINELli, D. S.; SORIANO, J. B.; FÁVARO, P. E. O profissional de Educação Física e a intervenção em equipes multiprofissionais. Movimento, v.15, n.4, p.35-62, 2009.

MOHR, P. A.; GUIMARÁES, A. V.; BARBOSA, A. R. Sintomas de distúrbios osteomusculares em profissionais de educação física, atuantes em academias de Florianópolis-SC. Revista Brasileira de Ciências do Esporte, v. 33, n. 4, p. 1041-1053, 2011.

MOLINA NETO, V. et. al. Reflexôes sobre a produção de conhecimento em educação física e ciências do esporte. Revista Brasileira de Ciências do Esporte, v. 28, p. 145-165, 2006.

MORAES, A. C. F. et al. Prevalência de inatividade física e fatores associados em adolescentes. Revista da Associação Médica Brasileira, v. 55, n. 5, p. 523-528, 2009.

NÓBREGA, T. P. Desafios da ciência, reflexão epistemológica e implicaçôes para a Educação Física e ciências do esporte. In: FERREIRA NETO, A. (Org.). Leituras da natureza científica do Colégio Brasileiro de Ciências do Esporte. Campinas: Autores Associados, 2005.p. 91-125.

OLIVEIRA, R. C. et al. Produção cientifica em Educação Física e cultura: revisão sistemática. Salusvita, v. 36, n. 2, p. 509-532, 2017.

OLIVEIRA, V. J. M.; MARTINS, I. R.; BRACHT, V. Projetos e práticas em educação para a saúde na educação Física escolar: Possibilidades! Revista de Educação Física - UEM, v. 26, n. 2, p. 243-255, 2015.

PACHECO, P. F. L.; TIRINTAN, M. M.; OLIVEIRA, R. C. A produção de conhecimento e o conceito de saúde numa graduação em Educação Física. Salusvita, v. 35, n. 2, p. 259-278, 2016.

PADILHA, M. I. et. al. Internationalization of knowledge and the enhancement of the quality and visibility of scientific Brazilian journals. Texto \& Contexto - Enfermagem, v. 23, n. 3, p. 517-518, 2014.

PAIVA, F. S. L.. A constituição do campo da educação física no Brasil: ponderações acerca de sua especificidade e autonomia. In: BRACHT, V.; CRISÓRIO, R. (Orgs.). A Educação Física no Brasil e na Argentina. Campinas: Autores Associados, 2003. p. 63-80.

PALMA, A.; ESTEVÃO, A.; BAGRICHEVSKY, M. Consideraçôes teóricas acerca das questóes relacionadas à promoção da saúde. In: BAGRICHEVSKY, M.; PALMA, A.; ESTEVÃO, A. (Orgs.). A saúde em debate na Educação Física. Blumenau: Edibes, 2003.p. 15-32.

PEDROSA, O. P.; LEAL, A. F. A inserção do profissional de Educação Física na estratégia saúde da família em uma capital do norte do Brasil. Movimento, v. 18, n. 2, p. 235-253, 2012.

PENTEADO, R. Z. et al. Desconfortos, sinais e sintomas vocais em Técnicos e Preparadores físicos de futebol. Distúrbios de Comunicação, v. 27, n. 4, p. 778-788, 2015. 
PENTEADO, R. Z.; SILVA, N. B. Voz e condiçôes de trabalho de técnicos e preparadores físicos de futebol. Distúrbios da comunicação, v. 26, n. 4, p. 790-799, 2014.

PENTEADO, R. Z.; SILVA, N. B.; MONTEBELLO, M. I. L. Voz, estresse, trabalho e qualidade de vida de técnicos e preparadores físicos de futebol. CoDAS, v .27, n. 6, p. 588-597, 2015.

POLIPPO, P. M. Produção científica brasileira sobre psicologia evolucionista. Gerais: Revista Interinstitucional de Psicologia, v. 9, n. 2, p. 277-289, 2016.

ROBLE, O. J.; MOREIRA, M. I. B.; SCAGLIUSI, F. B. A educação física na saúde mental: construindo uma formação na perspectiva interdisciplinar. Interface, v. 16, n. 41. p. 567-577, 2012.

SÁ, T. H.; FLORINDO, A. A. Efeitos de um programa educativo sobre práticas e saberes de trabalhadores da Estratégia da Saúde da Família para a promoção de atividade física. Revista Brasileira de Atividade Física e Saúde, v. 17, n. 4, p. 293-299, 2012.

SANTIAGO, M. L. E.; PEDROSA, J. I. S.; FERRAZ, A. S. M. A formação em saúde à luz do projeto pedagógico e das diretrizes curriculares da Educação Física. Movimento, v. 22, n. 2, p. 443-458, 2016.

SANTOS, B. S. Um discurso sobre as ciências. 6.ed.Porto: Afrontamentos, 1993.

SANTOS, S. F. S.; BENEDETTI, T. R. B. Cenário de implantação do Núcleo de Apoio a Saúde da Família e a inserção do profissional de Educação Física. Revista Brasileira de Atividade Física e Saúde, v. 17, n. 3, p. 188-194, 2012.

SANTOS, S. F. S. et al. The work of physical education professionals in Family Health Support Centers (NASF): a national survey. Revista Brasileira de Cineantropometria e Desempenho Humano, v. 17, n. 6, p. 693-703, 2015.

SAPORETTI, G. M.; MIRANDA, P. S. C.; BELISÁRIO, S. A. O profissional de Educação Física e a promoção da saúde em Núcleos de Apoio à Saúde da Família. Trabalho, Educação e Saúde, v. 14, n. 2, p. 523-543, 2016.

SEGRE, M.; FERRAZ, F. C. O conceito de saúde. Revista de Saúde Pública, v. 31, n. 5, p. 538542, 1997.

SCHUBERT, A. et al. Aptidão física relacionada à prática esportiva em crianças e adolescentes. Revista Brasileira de Medicina do Esporte, v. 22, n. 2, p. 142-146, 2016.

SILVA, D. A. S. Indicadores do estilo de vida e autoavaliação negativa de saúde em universitários de uma instituição pública do nordeste do Brasil. Revista Brasileira de Atividade Física e Saúde, v. 17, n. 4, p.263-269, 2012.

SILVA, D. A. S. et al. Estilo de vida de acadêmicos de Educação Física de uma universidade pública do estado de Sergipe, Brasil. Revista Brasileira de Ciências do Esporte, v. 34, n. 1, p. 53-67, 2012. 
SILVA, R. V. S. O CBCE e a produção do conhecimento em Educação Física em perspectiva. In: FERREIRA NETO, A. (Org.) Leituras da natureza científica do Colégio Brasileiro de Ciências do Esporte. Campinas: Autores Associados, 2005.p. 45-69.

SOUZA, J. C.; COSTA, D. S. Qualidade de vida de uma amostra de profissionais de educação física. Jornal Brasileiro de Psiquiatria, v. 60, n. 1, p. 23-27, 2011.

SOUZA NETO, S. et al. A formação do profissional de educação física no Brasil: uma história sob a perspectiva da legislação federal no século XX. Revista Brasileira de Ciências do Esporte, v. 25, n. 2, p. 113-128, 2004.

XAVIER, D. A.; KNUTH, A. G. Mapeamento da Educação Física em programas de Residência Multiprofissional em saúde no sul do Brasil. Revista Brasileira de Atividade Física e Saúde, v. 21, n. 6, p. 552-560, 2016.

\section{Notas}

${ }^{1}$ Embora o termo "Ciências do Esporte" apareça relacionado à produção científica da área nesse período, dentre outros (Ciência da Motricidade Humana, Ciência do Movimento Humano etc.) nos remetemos a Bracht (2000), para o qual a EF não é uma ciência, mas uma área do conhecimento científico que se debruça sobre o movimentar-se humano. Para o autor, a suposta uniáo da EF com a ciência foi um movimento ordenado com vistas ao ganho de legitimidade acadêmica.

${ }^{2}$ Aqui entendido como manifestação cultural que se evidencia na dimensão corporal (LAZZAROTTI FILHO et al., 2010). Nessa perspectiva, todo o escopo de práticas ligadas à cultura de movimento, a saber: esporte, dança, ginástica, lutas, jogo etc. Já os termos “atividade física” e "exercício físico”, embora não sendo sinônimos, mas muito comuns na área, serâo utilizados no manuscrito no contexto do diálogo com os autores que os propõem.

${ }^{3}$ Em nossa compreensão, a inserção da EF nas Ciências da Saúde no âmbito da CAPES não significou estreitamento de políticas de cuidado em saúde, mas sim na organização epistemológica da área, que, nesse período, iniciava a vivência de sua crise de identidade, reportada em vários estudos (DAOLIO, 1998; BRACHT, 1999, dentre outros), gerando mais reordenamentos de percurso de formação no ensino superior (licenciatura $\mathrm{x}$ bacharelado) do que um real enlace com a saúde.

${ }^{4} \mathrm{O}$ conceito de saúde documentado neste evento a trata como resultante das condições de alimentação, habitação, renda, meio ambiente, trabalho, transporte, emprego, lazer, liberdade, acesso e posse da terra e acesso aos serviços de saúde (BRASIL, 1986).

${ }^{5}$ Alguns estudos se valeram de mais de um instrumento na coleta de dados.

${ }^{6}$ A. D. Lotti e R. C. de Oliveira trabalharam em todas as etapas do manuscrito, desde sua concepção, redação, revisão e aprovação da versão final. C. F. B. de Oliveira, J. R. A. Dias, E. O. Borges e J. Koumantareas realizaram análise e interpretação dos dados, redação, revisão e aprovação da versão final. 


\section{Abstract}

\section{Knowledge production on Physical Education and health in Brazilian journals}

This study aimed to analyze knowledge production in Physical Education and health in Brazilian journals. For this, bibliographic research was developed in the Lilacs database. Data collection took place through the descriptor "physical education and health" comprising publications between 1997 and 2017. The sample consisted of 46 articles, which were characterized in terms of authorship, journal, evaluation in the Qualis Capes system, type of study, methodological approach, data collection instruments, methodological sampling, topics covered, area of dialogue and health concept. The results showed that scientific production has been demanded by Brazilian researchers and with a focus on the theme of professional performance, mostly published in journals with B1 and B2 evaluations. Although the theoretical aspect of Human Sciences is predominant, the quantitative methodological approach still has a greater number of publications. As for the concept of health, the expanded perspective was present in 17 studies, however 26 studies did not conceptualize health, which we consider a worrying factor. It was concluded that the production of knowledge in Physical Education and health in Brazilian journals is diverse in terms of themes and approaches, however, it still lacks deepening on the concept of health.

> Keywords: knowledge; health sciences; periodicals. 